\title{
Versicherungs- und Bankrecht
}

\author{
Inhaltsübersicht
}

\author{
A. Privatversicherungsrecht \\ I. Die Anfänge \\ 1. Vor dem Ersten Weltkrieg \\ 2. Weimarer Zeit \\ 3. Vor dem Zweiten Weltkrieg \\ 4. Im Zweiten Weltkrieg \\ 5. Die Jahre bis 1970 \\ 6. Das Alles-oder-nichts-Prinzip \\ 7. Gegenwart \\ B. Bankrecht \\ I. Entwicklung bis heute \\ II. Grenzen der Mithaftung für Darlehensschulden \\ III. Die Freigabe von revolvierenden Globalsicherungen \\ IV. Heininger und die Folgen \\ V. Ausblick
}

\section{A. Privatversicherungsrecht}

\section{Die Anfänge}

\section{Vor dem Ersten Weltkrieg}

Der Verlag C. H. Beck beschäftigt sich gleich nach dem Inkrafttreten des Gesetzes über die privaten Versicherungsunternehmen vom 12. Mai 1901 (Versicherungsaufsichtsgesetz) mit dem Privatversicherungsrecht. Hermann Rehm gibt den Gesetzestext nur wenig später erstmals heraus; die Textausgabe erreicht die dritte Auflage bereits im Jahre 1911. Davor liegen sporadische Veröffentlichungen aus unterschiedlichen, aber nicht systematisierten Themenbereichen. E. Reinbeck veröffentlicht 1905 die Haftung der Versicherungsforderung für Hypotheken und Grundschulden. Thomas Hauck kommentiert die Brandversicherungsgesetze für das Königreich Bayern in der Fassung des Art. 164 des Ausführungsgesetzes zum Bürgerlichen Gesetzbuch vom 9. Juni 1899. Die vierte Auflage, bearbeitet von Hermann Stöhr, erscheint bei C. H. Beck im Jahre 1907. Waldemar Scheel veröffentlich im Jahre 1911 eine Schrift über den Vorstand des Versicherungsvereins auf Gegenseitigkeit nach dem Reichsgesetz über die privaten Versicherungsunternehmen vom 11. 5. 1901 und Fritz Stier-Solmo präsentiert eine Handausgabe zur Reichsversicherungsordnung vom 19. Juli 1911 nebst Anhang und Sachregister im Jahre 1913. 
Der Erste Weltkrieg reißt eine Lücke in das erst beginnende Verlagsprogramm zum Privatversicherungs- (und zum Sozialversicherungs-) recht. Von der großen, bis heute das Privatversicherungsrecht bestimmenden Kodifikation des Versicherungsvertragsgesetzes aus dem Jahre 1908 ist bis zum Jahre 1927 beim C.H. Beck-Verlag nichts zu sehen. Das galt auch bereits für die zahlreichen Versuche, die nach Inkrafttreten des Allgemeinen Preußischen Landrechts im Jahre 1794 unternommen wurden, um für das Privatversicherungsrecht eine brauchbare Kodifikation zu schaffen. ${ }^{1}$ Impulse dazu gingen zunächst vom Entwurf eines Handelsgesetzbuches für das Königreich Württemberg 1840 aus. Auch Preußen, das mit dem ALR die erste versicherungsrechtliche Kodifikation des gesamten Versicherungsrechts besaß ${ }^{2}$, legte 1857 eine neue Regelung innerhalb des Entwurfs eines Handelsgesetzbuches für die Preußischen Staaten vor. Dieser Entwurf lag den Arbeiten der Nürnberger Konferenz von 1857-1861 zur Beratung eines Allgemeinen Deutschen Handelsgesetzbuches (ADHGB) zugrunde. Allerdings wurden nach den Beratungen in Hamburg nur die seeversicherungsrechtlichen Vorschriften (Artt. 782-905) verabschiedet. Diesen Standort nehmen sie auch im geltenden Handelsgesetzbuch noch ein. Eine Kodifikation des Binnenversicherungsrechtes wurde gar nicht erst erörtert. Die Kommission war der Auffassung, insoweit nicht über genügend Informationen zu verfügen. Auch der Entwurf eines Bürgerlichen Gesetzbuches für das Königreich Bayern (1861) sowie der Dresdener Entwurf eines Allgemeinen Deutschen Obligationenrechtes (1866) befaßten sich mit dem Versicherungsrecht, blieben aber im Ansatz stecken.

Entscheidende Bedeutung für die Kodifikationsgeschichte des 19. Jahrhunderts kommt demgegenüber der Entwicklung der Allgemeinen Versicherungsbedingungen zu. Das liegt angesichts der fehlenden Gesamtkodifikation durchaus nahe. So entstanden als Folge der sich ausweitenden Geschäftstätigkeit der Gesellschaften die ersten einheitlichen Bedingungen auf Verbandsebene (1874), deren Wirkung zum Teil weit über den Einzelvertrag hinausgehend bis in das spätere Versicherungsvertragsgesetz (VVG) zu verfolgen ist. So hat der das Programm des C.H. Beck-Verlages später entscheidend prägende Erich R. Prölss zeigen können, daß wesentliche Regelungen der Feuerversicherungsbedingungen, wie etwa der Übergang von Regreßansprüchen auf den Versicherer ( $\$ 67$ VVG) oder das Recht der Kündigung nach dem Schadensfall ( $\$ 96$ VVG), direkt Eingang in das VVG gefunden haben. ${ }^{3}$ Vorläufer auch dieser Entwicklung war wieder das Seeversicherungsrecht. Denn obwohl die Seeversicherung in den Artt. 782-905 ADHGB kodifiziert worden war, blieb ihr Anwendungsbereich gering, weil sich die Praxis,

\footnotetext{
1 Überblick bei Peter Koch, Zur Geschichte der versicherungsvertragsrechtlichen Kodifikationen in Deutschland und Österreich in: FS für Reimer-Schimdt 1976, 299, 315 ff.; Viktor Ehrenberg, Versicherungsrecht Band I, 1893, S. $41 \mathrm{ff}$.

2 Das am 1. 6. 1794 in Kraft getretene Preußische Allgemeine Landrecht (ALR) war ein Monumentalwerk, das im wesentlichen auf der Leistung des Geheimen Obertribunalrats Carl Gottlieb Suarez beruhte. Es enthielt im Teil II, Titel 8 in den $\$ \S 1934-2358$ das gesamte Versicherungsrecht der damaligen Zeit.

${ }^{3}$ E.R. Prölss, Die Entwicklung des Feuerversicherungsrechts, in: Das Versicherungsarchiv 1942/43, S. 156, $162 \mathrm{f}$.
} 
wie auch heute noch, an den anschaulicheren Allgemeinen Seeversicherungsbedingungen von 1867 (ADS) orientierte. ${ }^{4}$

Als nach der Entstehung des Deutschen Reiches (1871) die Voraussetzungen für eine reichseinheitliche Regelung des Bürgerlichen Rechts gegeben waren, stand auf dem Plan auch eine gesetzliche Regelung des Versicherungsrechts. ${ }^{5}$ Dieses Vorhaben wurde in der zweiten Lesung ${ }^{6}$ jedoch aufgegeben, nachdem sich herausstellte, daß das sich parallel zum BGB entwickelnde spätere Versicherungsaufsichtsgesetz (VAG) bis zum Inkrafttreten des BGB nicht fertiggestellt werden konnte. Diese enge Verknüpfung des Privatversicherungsrechts mit dem Aufsichtsrecht beruhte auf dem Verlangen verschiedener einflußreicher Gremien, vor allem den volkswirtschaftlichen Congressen von 1861 und 1865, dem Deutschen Juristentag 1862 und dem Deutschen Handelstag 1865. ${ }^{7}$

Die Rechtsgrundlage für das spätere VAG bot dann Art. 4 der Verfassung des Norddeutschen Bundes, die später in die Verfassung des Deutschen Reiches einging. Die Bemühungen zur Schaffung des VAG führten schließlich zu dem am 14. November 1900 vorgelegten Entwurf eines Gesetzes über die privaten Versicherungsunternehmen, das am 12. Mai 1901 verkündet wurde und am 1. Januar 1902 in Kraft trat. Das VAG enthält allerdings nicht nur Aufsichtsrecht, sondern neben unternehmensrechtlichen Bestimmungen auch den Versicherungsvertrag betreffende privatrechtliche Elemente und bildet insoweit eine Einheit mit dem späteren VVG. Dieses Gesetz über den Versicherungsvertrag wurde ab Mai 1903 zunächst eingehend beraten und schließlich am 30. Mai 1908 im Reichsgesetzblatt verkündet. Es trat aufgrund der zuvor notwendigen aufsichtsrechtlichen Genehmigungen der Versicherungsbedingungen erst am 1. Januar 1910 in Kraft. Das Verlagsprogramm des C. H. Beck-Verlages wurde davon aber nicht berührt.

\section{Weimarer Zeit}

Das ändert sich erstaunlicherweise erst im Jahre 1927, als Ernst von Bruck die Sammlung der das Private Versicherungsrecht betreffenden Gesetze und Verordnungen in einer Textausgabe mit Verweisungen und Sachverzeichnis herausgibt. Mehr passiert in den bewegten Weimarer Jahren im Programm des C. H. BeckVerlages auf dem Gebiet des Privatversicherungsrechts jedoch nicht.

\section{Vor dem Zweiten Weltkrieg}

Fast möchte man sagen, daß sich an diesem Befund auch in den Jahren von 19331938 wenig ändert. Tatsächlich aber legt der Verlag zu dieser Zeit die entscheidenden Wurzeln, die das Verlagsprogramm im Privatversicherungsrecht künftig grundlegend prägen, gestalten und weiterentwickeln werden. 1935 erscheint die erste Auflage des Kommentars zum Versicherungsvertragsgesetz von Erich

${ }^{4}$ Ritter Abraham, Das Recht der Seeversicherung, Kommentar, Band I, Vorbemerkungen I, Anm. 6.

5 Bruck, Privatversicherungsrecht, 1930, S. 13.

6 Protokolle zum BGB, Band 6, S. 440, 471, 610.

7 Kraus, Versicherungsaufsichtsrecht, 1971, S. $5 \mathrm{ff}$. 
R. Prölss. Er wird zur Lichtgestalt des Privatversicherungsrechts des 20. Jahrhunderts schlechthin werden - ohne ihn ist die gesamte Entwicklung des Programms im C.H. Beck-Verlag, aber auch bei allen anderen Wissenschaftsverlagen der Bundesrepublik, nicht denkbar. Nur drei Jahre nach der Veröffentlichung des ersten Versicherungsvertragsgesetzes von Erich R. Prölls erscheint von G. E. Fromm der Kommentar zum Versicherungs- und Bausparkassenaufsichtsgesetz, der später unter dem prägenden Einfluß von Schmidt, Prölss, Frey zum führenden und über viele Jahrzehnte fast einzigen Kommentar auf diesem Gebiet werden soll.

Aber zurück zum alle überragenden Erich R. Prölss. Er schreibt im Vorwort seines Kommentars zum Versicherungsvertragsgesetz im Jahre 1935:

„Ich habe mich bemüht, einen Kommentar für Praktiker zu schreiben. Erläutert ist daher nur was wichtig ist, und nur in dem Umfang, wie es wichtig ist. Ein guter Maßstab sind die veröffentlichten Urteile.

Ich habe mich im wesentlichen auf die Rechtsprechung gestützt. Zitiert sind daneben mit wenigen Ausnahmen nur die Standardwerke des Versicherungsrechts, benutzt ist das gesamte Schrifttum. Entscheidungen habe ich in Auswahl angefuhrt. Vollständigkeit ist nicht angestrebt. Es ist dem Praktiker nicht erwünscht, wenn er einen vom Reichsgericht dutzendmal ausgesprochenen Satz in einer 13. oder 14. Entscheidung nur wiederholt findet. Dafür habe ich lieber einmal ein gutes Landgerichtsurteil erwähnt. Bei Fragen, die noch im Fluß sind, habe ich mehr Material gegeben. ...

Den Praktiker kümmert nur das lebende Versicherungsrecht. Ich mußte dabei im weiten Umfange das Vertragsrecht verwerten. Ein bloßer Hinweis auf diese oder jene Bestimmung der Allgemeinen Versicherungsbedingungen genügt dem Praktiker nicht; es kommt häufig auf den genauen Wortlaut an, vielfach auch im Gegensatz zu der Formulierung, den die Bedingungen anderer Versicherungszweige für die gleiche oder ein ähnliche Vorschrift gewählt haben. ...

Mit diesem Vorwort hat Erich R. Prölss nicht nur Rechts-, sondern auch Verlagsgeschichte geschrieben. Entscheidend wurde von nun an in Literatur und Rechtsprechung, was er für richtig hielt und in welchem Umfange er es für wichtig hielt. Die Klarheit der Diktion, die präzise und bestimmte Satzführung, die Prägnanz der Argumente bestimmten von nun an den Ton in Literatur und Rechtsprechung des Privatversicherungsrechtes. Was Prölss dachte, wurde beachtet und in aller Regel auch befolgt. Es wird immerhin 62 Jahre dauern, bis der „Prölss“, der heute das Standardwerk des Privatversicherungsrechtes schlechthin ist, im eigenen Haus durch einen neuen Kurz-Kommentar ergänzt wird, der den inzwischen im Dünndruck erscheinenden, viele tausend Seiten umfassenden Prölss auf das Format des Jahres 1935 zurückführt - die Rede ist vom Römer/Langheid. Bis dahin ist es noch lange hin.

Im Jahre 1962 wird Prölss erstmals das Österreichische Recht in seine Kommentierung aufnehmen. Im Jahre 1967 wird ihn die Hamburger Universität zum Honorarprofessor machen. Kurz danach, im Jahre 1968, wird er die 17. Auflage seines Lebenswerkes abschließen und den Stab an die neuen Autoren Anton Martin sowie seinen Sohn, Jürgen Prölss, der damals noch wissenschaftlicher Assistent und heute emeritierter Professor der Freien Universität Berlin ist, abgeben. 1992 - die 
25. Auflage erscheint - kommen Ulrich Knappmann, Vorsitzender Richter am OLG Hamm, Helmut Kollhosser (Prof. an der Universität Münster) und Wolfgang Voit (Vorsitzender Richter am OLG a.D.) hinzu. Anton Martin, der bereits mit 50 Jahren am 14. Mai 1990 verstirbt, hinterläßt ein breites und geniales Lebenswerk und eine ebenso große Lücke, die bis heute nicht wirklich geschlossen ist. Im Jahre 2004 tritt Christian Armbrüster (Professor an der Freien Universität Berlin und Schüler von Jürgen Prölss) in das Autorenteam ein. Der „Prölss“ erscheint in der 27. Auflage und im neuen Format - er ist $\mathrm{zu}$ einem großen ausladenden Handkommentar geworden.

\section{Im Zweiten Weltkrieg}

Von der ersten, im Jahre 1935 erschienenen Auflage des Prölsschen Kommentars zum VVG bis zur 2. Auflage von 1940 dauert es immerhin fünf Jahre, dann aber erscheinen bis zum Jahre 1943 gleich zwei weitere Auflagen, so als gäbe es den Zweiten Weltkrieg nicht und alle Welt würde sich mit dem Privatversicherungsrecht beschäftigen.

\section{Die Jahre bis 1970}

Der Einschnitt des Kriegsendes macht sich in der Verlagsredaktion zum Versicherungsrecht noch stärker bemerkbar als der Krieg selbst. Die 5. Auflage des „Prölss“ erscheint erst im Jahre 1948. Von nun beginnt der für Prölss typische Zwei-JahresRhythmus, die 6. Auflage kommt im Jahre 1950, die 7. Auflage im Jahre 1952, die 8. Auflage 1954, die 9. Auflage 1956 und die 10. - diesmal wird der Rhythmus auf ein Jahr verkürzt - schon im Jahre 1957.

Zwischen diesen laufenden Aktivitäten übernimmt Prölss von Fromm die Herausgabe des Versicherungsaufsichtsgesetzes, erstmals im Jahre 1953. 1955 erscheint dann die erste Auflage des von Prölss verfaßten Kommentars zum Versicherungsaufsichtgesetz. Die 2. Auflage erscheint zeitgleich mit der 10. Auflage zum VVG im Jahre 1957. Dann werden die Abstände größer. Die 3. Auflage zum VAG kommt im Jahre 1961 und die letzte von Erich R. Prölss selbst bearbeitete 5. Auflage im Jahre 1966.

Bisher besteht das Verlagsprogramm praktisch aus den Werken von Erich R. Prölss. Sehr viel ändert sich daran auch nicht bis zum Jahre 1970. Nur zwei Autoren gelingt es in dieser Zeit, das Verlagsprogramm zu erweitern. Der eine ist Heinrich Krebs, der 1957 das Gesetz über Arbeitsvermittlung und Arbeitslosenversicherung kommentiert und 1961 eine erweiterte 2. Auflage herausbringt. Dazwischen aber präsentiert Prölss selbst noch einen Kommentar zu § 102 des am 1. Januar 1958 in Kraft getretenen Gesetzes gegen Wettbewerbsbeschränkungen. Inhalt ist das Kartellrecht der Versicherungswirtschaft. Prölss dürfte gespürt haben, daß mit diesem Gesetz in der jungen Bundesrepublik Deutschland eine neue Ära begann, die Ära der Demokratisierung der Deutschen Wirtschaft, der Abschied von den Kartellen und Monopolen. Das alles aber geschieht nur behutsam und ganz langsam, denn die Versicherungswirtschaft ist - so wie die Bankwirtschaft oder die Energiewirtschaft - von den Wirkungen des neuen GWB zunächst noch 
ausgenommen. Der zeitgleich in Kraft tretende EWG-Vertrag enthält ebenfalls erstmals Wettbewerbsregeln, die Kartelle und mißbräuchliche Verhaltensweisen marktbeherrschender Unternehmen verbieten und den Monopolen den Kampf ansagen. Die vertragsschließenden sechs europäischen Kernländer (Frankreich, Italien, Benelux und Deutschland) glauben für die Verwirklichung des Binnenmarktes und die gegenseitige Anerkennung ihrer Rechts- und Wirtschaftssysteme eine Übergangszeit von zwölf Jahren zu benötigen. Das alles wird nichts werden - erst im Jahre 1987 wird der Europäische Gerichtshof entscheiden, daß die Regeln der Dienstleistungsfreiheit auch auf Versicherungsmärkten gelten und erst im Jahre 1994 wird es zur Öffnung und Liberalisierung der Versicherungsmärkte kommen.

Ob Erich R. Prölss dies alles gespürt hat, als er sich im Jahre 1958 entschloß den Kommentar zum $\S 102$ GWB im C.H. Beck-Verlag zu verfassen, erscheint eher unwahrscheinlich, aber immerhin die große Bedeutung, die dieses zukünftige „Grundgesetz der Deutschen Wirtschaft“" haben wird, muß er sofort erkannt haben und es muß ihm wichtig gewesen sein, die Meinungsfürerschaft bei diesem „Grundgesetz der Bundesdeutschen Wirtschaft“ von Anfang an zu übernehmen. Bereits 1961 wird er die Kommentierung zu $\S 102$ GWB in die 3. Auflage zum VAG integrieren und 1962 wird Prölss auf seine Weise die Idee des Binnenmarktes vorantreiben. In der 13. Auflage wird viele Jahre vor der Aufnahme Österreichs in die Europäische Union erstmals die Österreichische Rechtsprechung zum Privatversicherungsrecht berücksichtigt. Prölss bedankt sich ausdrücklich bei Wahle und Sasse für die Mithilfe. Bis 1968 erscheinen weitere vier Auflagen des VVGKommentars - mit der 14. Auflage im Jahre 1963 wird ein moderneres neues Schriftbild eingeführt.

Der Wissenschaftsmarkt im Bereich des Privatversicherungsrechtes gehört in den fünfziger und sechziger Jahren Erich R. Prölss - jedenfalls soweit es um den C.H. Beck-Verlag geht. So ist es auch ihm vorbehalten, in den sechziger Jahren eine jener Innovation auszulösen, die später zu einem ganzen Verlagsprogramm führen wird. Es erscheint die Kommentierung zum Recht der EinbruchDiebstahl-Versicherung so, als handelte es sich dabei um ein Gesetz und nicht nur um Allgemeine Versicherungsbedingungen. Bereits 1966 erscheint die 3. Auflage. Ein Jahr später - Prölss wird zum Honorarprofessor an der Universität Hamburg ernannt - veröffentlicht Franz Büchner seinen Beitrag zur Geschichte der Gebäudeneuwertversicherung in Deutschland, während Prölss im selben Jahr die 16. Auflage des VVG bearbeitet. 1968 erscheint dann die 17. und damit zugleich die letzte von Erich R. Prölss selbst bearbeitete Auflage zum VVG. Die Ära des prägendsten Versicherungsrechtlers, den die Bundesrepublik Deutschland im 20. Jahrhundert hatte, neigt sich dem Ende zu. Sein Name lebt bis heute fort - aber mit dem Ende der sechziger Jahre wirft der erste Generationenwechsel im Privatversicherungsrecht seine Schatten voraus - der zweite wird dann gegen Ende des Jahrhunderts mit dem „Römer/Langheid“ eingeläutet werden. 


\section{Das Alles-oder-nichts-Prinzip}

In den 60er Jahren des vergangenen Jahrhunderts bahnt sich auch einer der zentralen Konflikte an, der unter dem Namen Alles-oder-nichts-Prinzip bekannt ist und im Jahre 2000 die Justizministerin (Herta Däubler-Gmelin) veranlaßt, eine VVGReformkommission einzusetzen. Die Reformkommission, die ihren Abschlußbericht im April 2004 vorlegt, wird vorschlagen, das Alles-oder-nichts-Prinzip gegen ein am Schweizer Vorbild orientiertes Quotensystem auszuwechseln. Die Vorboten für diesen für das gesamte VVG absolut grundlegenden Paradigmenwechsel werden in den 60er Jahren des vergangenen Jahrhunderts erkennbar.

Was ist mit dem Alles-oder-nichts-Prinzip gemeint? Der Grundgedanke ist einfach: Ein Versicherungsnehmer, der seine Verhaltenspflichten gegenüber dem Versicherer verletzt, z.B. eine versprochene Alarmanlage nicht einbaut, ohne Führerschein fährt, die Fenster zur Wohnung offen läßt, so daß der Dieb leicht einsteigen kann, verliert den Anspruch auf die Versicherungsleistung, jedenfalls dann, wenn er damit den Versicherungsfall vorsätzlich oder durch grobe Fahrlässigkeit herbeiführt ( $\$ 61 \mathrm{VVG})$. Das gilt auch bei Obliegenheitsverletzungen vor oder nach dem Versicherungsfall, also Verhaltenspflichten, die im Vertrag ausdrücklich vereinbart worden sind ( $\$ 6$ VVG). Verletzt der Versicherungsnehmer seine Verhaltenspflichten stark, so bekommt er folglich nichts - verletzt er seine Pflichten weniger stark, so bekommt er alles.

Dieses Alles-oder-nichts-Prinzip hat $\S 6$ Abs. 3 VVG schon immer leicht eingeschränkt. Bei grobfahrlässiger Verletzung bleibt der Versicherer nämlich zur Leistung insoweit verpflichtet, als die Verletzung weder auf die Feststellung des Versicherungsfalles noch auf den Umfang seiner Leistung Einfluß gehabt hat. Das Alles- oder Nichts-Prinzip findet sich in Form von Verhaltenspflichten an verschiedenen anderen Stellen im VVG, so z. B. bei den vorvertraglichen Anzeigepflichten ( $\S 16 \mathrm{ff}$. VVG), bei der Gefahrerhöhung bei Vertragsschluß ( $\S 23 \mathrm{ff}$. VVG), bei der Schadensabwendungs- und minderungspflicht sowie den Rettungskosten ( $\S 62,63$ VVG) und bei der Veräußerungsanzeige ( 71 VVG). Stein des Anstoßes ist das Alles-oder-nichts-Prinzip deshalb, weil nicht jeder, der grob fahrlässig oder vorsätzlich seine Verhaltenspflichten verletzt, dies in der Absicht tut, sich einen ungerechtfertigten Vermögensvorteil $\mathrm{zu}$ verschaffen. So verschweigen Versicherte, die bei einem leichten Verkehrsunfall angetrunken waren, diese Tatsache häufig auch in der Schadenanzeige gegenüber dem Versicherer. Sie glauben, dafür keinen Versicherungsschutz zu haben, obwohl § 152 VVG das Gegenteil regelt. Folge - für die Trunkenheit selbst waren sie zwar versichert, aber sie verlieren den Versicherungsschutz, weil sie ihre Aufklärungspflichten vorsätzlich verletzen. In diesen Fällen haben die Versicherer den Versicherungsschutz entzogen und sind damit leistungsfrei geworden, obwohl sich die Obliegenheitsverletzung weder auf die Feststellung noch auf den Umfang des Versicherungsfalles ausgewirkt hat. Die Obliegenheitsverletzung ist folglich überhaupt nicht relevant geworden, eine Tatsache, die beim BGH in den sechziger Jahren des letzten Jahrhunderts zunehmend Stirnrunzeln und in Folge davon die ,Relevanzrechtsprechung“ ausgelöst hat. Umgekehrt gibt es natürlich Versicherungsnehmer, die ihre Verhaltenspflich- 
ten verletzen, um sich auf diese Weise ungerechtfertigte Vermögensvorteile zu verschaffen. Typisches Beispiel ist der Versicherungsnehmer, bei dem eingebrochen wird und auf dessen „Stehlgutliste“ sich plötzlich Dinge befinden, die er in Wahrheit nie besessen hat. In diesen Fällen kann eine an der Schwere des Verhaltensvorwurfs orientierte Sanktion zu Lasten des Versicherungsnehmers durchaus gerechtfertigt sein. Das Gesetz beugt auf diese Weise dem Anreiz von Versicherungsnehmern vor, sich im Schadensfall zu Lasten der Versichertengemeinschaft unrechtmäßig zu bereichern. Man spricht in diesem Fall vom moralischen Risiko.

Der Gesetzgeber des VVG hat sich die Sache im 19. Jahrhundert verhältnismäßig leicht gemacht und als Generalprävention das Alles-oder-nichts-Prinzip entwickelt, ganz gleichgültig, ob der Versicherungsnehmer im Einzelfall die Absicht hatte, sich zu bereichern oder nicht. Damit haben Versicherte über viele Jahrzehnte ihren Versicherungsschutz auch dann verloren, wenn ihre Pflichtverletzung für die Feststellung oder den Umfang des Versicherungsfalls irrelevant war und es hat in diesen Fällen noch nicht einmal eine Prüfung der Frage stattgefunden, ob der Umfang des Schadens, den Versicherte in diesen Fällen selbst tragen mußten, in angemessener Relation zum Verhaltensverstoß lag. Damit ging das Alles-oder-nichts-Prinzip weit über die Grundprinzipien des Strafrechtes hinaus. Denn im Strafrecht gilt der Grundsatz, daß jeder nach Maßgabe seiner individuellen Schuld zu bestrafen ist. Dies ist der Grund, warum auf der einen Seite zwischen Freiheits- und Geldstrafe und auf der anderen Seite zwischen der Länge der Freiheitsstrafe und der Menge der Tagessätze differenziert wird.

Eine vergleichbare an der Schuld des Versicherungsnehmers orientierte angemessene und in sich abgewogene Differenzierung findet beim Alles-oder-nichtsPrinzip nicht statt. Ein Versicherungsnehmer, der die Unfallstelle verläßt und damit vorsätzlich Fahrerflucht begeht, um nach zweihundert Metern umzukehren und zur Rettung der Verletzten und zur Aufklärung des Versicherungsfalles beizutragen, verliert seinen Versicherungsschutz, weil er die Unfallstelle zunächst vorsätzlich verlassen hat und die reumütige Rückkehr daran nichts ändert. Die tatbestandlichen Voraussetzungen von $§ 6$ Abs. 3 VVG sind erfüllt - der Versicherer ist von der Verpflichtung zur Leistung frei, obwohl der Pflichtenverstoß des Versicherungsnehmers weder für die Feststellung noch für den Umfang des Versicherungsfalles auch nur ansatzweise relevant waren. Dies sind die Fälle, die die Bundesministerin der Justiz im Jahre 2000 veranlaßt haben, eine VVG-Reformkommission einzuberufen, um ihr unter anderem die Frage zu stellen, ob es zeitgemäß ist, am Alles-oder-nichts-Prinzip festzuhalten oder dies zu überwinden.

Schaut man einmal in die Kommentierungen von Erich R. Prölss, so findet man das Alles-oder-nichts-Prinzip als Begriff zunächst gar nicht. In der ersten Auflage seines berühmten Kommentars aus dem Jahre 1935 schreibt Prölss zwar, daß es schwierig ist, zwischen Obliegenheiten und objektiven Risikoausschlüssen abzugrenzen. ${ }^{8}$ Zur Leistungsfreiheit schreibt er, daß sie in den Allgemeinen Versicherungsbedingungen ausdrücklich vorgesehen sein müsste. Er fährt fort: „,Von der Verpflichtung zur Leistung frei“ - der Begriff stammt aus dem BGB (§§ 273, 275,

$8 \S 6$ Ziff. 3. 
776, 1165, 1181 Abs. 2) - bedeutet, daß der Versicherer ,nichts, aber auch gar nichts zu leisten hat"“9; nicht etwa tritt Verwirkung nur insoweit ein, als ein ursächlicher Zusammenhang zwischen Obliegenheitsverletzung und Eintritt oder Umfang des Schadens besteht. Zu berücksichtigen ist jeder einzelne Verstoß, nicht das „Gesamtverhalten“: ${ }^{10}$ Der Vertrag als solcher bleibt unberührt; der Versicherungsnehmer muß die Prämien weiterzahlen (RG 130, 271); für künftige Versicherungsfälle bleibt die Ersatzpflicht vorbehaltlich erneuter Verwirkung bestehen. Die Leistungsfreiheit tritt von selbst ein. Der Versicherer erhält nicht etwa nur ein Leistungsverweigerungsrecht. ${ }^{11}$ Die Leistungsfreiheit ist daher, wenn die tatsächliche Grundlage dem Gericht bekannt ist, von Amts wegen zu beachten.

Etwas weiter beschäftigt sich Erich R. Prölss mit Einschränkungen: „Der Feuerversicherer bleibt den Realgläubigern gegenüber verpflichtet: $\$ \S 101 \mathrm{ff}$. Bei rückkaufsfähigen Lebensversicherungen muß er dem Versicherungsnehmer die Prämienreserve herausgeben ( $\$ 176)$. Die Leistungsfreiheit bezieht sich nur auf den vertraglichen Entschädigungsanspruch, nicht auf einen daneben bestehenden Anspruch auf Schadensersatz gegen den Versicherer. ${ }^{12}$

Die entscheidende Passage in der Kommentierung von Erich R. Prölss lautet, daß der Versicherer ,nichts, aber auch gar nichts zu leisten hat“, daß es also nicht auf einen ursächlichen Zusammenhang zwischen Obliegenheitsverletzung und Eintritt oder Umfang des Schadens ankommt. Dem RG, und ihm folgend Erich R.Prölss, war die Wirkung des Alles-oder-nichts-Prinzips also voll bewußt. Eine differenzierte Betrachtungsweise zwischen den Fällen, in denen sich der Versicherungsnehmer zu Lasten der Versichertengemeinschaft bereichern wollte und jenen, in denen sein Pflichtenverstoß für Eintritt und Umfang des Schadens irrelevant war, wird ausdrücklich abgelehnt, ohne die damit verbundenen Probleme zu diskutieren und ohne über die Frage nachzudenken, ob damit das Verbot der Doppelbestrafung oder das der Angemessenheit von Sanktionen im Zivil- und Strafrecht möglicherweise verletzt ist. Die Entscheidungen, die Prölss zitiert, sind Ausdruck des Zeitgeistes, ihnen haftet nichts spezifisch Nationalsozialistisches an. Es wird in starren begrifflichen Kategorien gedacht. Der Zweck im Recht, wie er von Rudolph von Ihering in seiner berühmt gewordenen Schrift aus dem Jahre 1883 beschworen wurde, braucht noch viele Jahrzehnte, bevor er sich als ,Funktionsbezug des Rechts“ in den Köpfen der Juristen und in den Methodenlehren der Lehrbücher durchsetzen wird.

Das Reichsgericht verschärfte allerdings seine Rechtsprechung zur Leistungsfreiheit und entschied in $R G Z$ 157, 67: „Es kann genügen, wenn sich aus dem Vertragsinhalt ergibt, daß die Verwirkung als selbstverständliche Folge von Vertragsverstößen vorausgesetzt wird“. In diesen Fällen muß die Obliegenheitsverletzung im Vertrag folglich nicht vereinbart sein. Prölss führt in der 4. Auflage $(1943)^{13}$ fort: ,Außerdem kann nach der neuen Rechtsprechung des $R G$ die An-

${ }^{9}$ RG VU 26 Nr. 1652 = JR $1999=$ JW 972.

${ }_{10} R G$ JR 33, 232.

${ }_{11} R G$ JR 32, $72=$ JW 32, 2538.

12 RG JR 28, 85.

$13 \S 6$ Ziff. 9. 
wendung des $\S 242$ BGB dazu führen, daß der Versicherungsnehmer bei groben Verletzungen tragender Obliegenheiten seinen Anspruch ganz oder teilweise verliert, auch wenn Verwirkung nicht vereinbart wurde." ${ }^{14}$ Etwas weiter ist nun erstmals vom Alles-oder-nichts-Prinzip die Rede. Erich R. Prölss schreibt: „Dieses Alles-oder-nichts-Prinzip gilt uneingeschränkt nur für einfache vor dem Versicherungsfall zu erfüllende Obliegenheiten und für die vorsätzliche Verletzung nach dem Versicherungsfall zu erfüllender. Ausnahmen: a) Obliegenheiten, die der Verminderung der Gefahr oder der Verhütung einer Gefahrerhöhung dienen, II: Keine Verwirkung, wenn die Verletzung keinen Einfluß auf den Eintritt des Versicherungsfalls oder den Umfang der dem Versicherer obliegenden Leistung gehabt hat. Es darf aber nicht die allergeringste Kausalität in Bezug auf den Eintritt des Versicherungsfalls oder auf den Umfang der Leistung des Versicherers vorliegen, wie in $\S 21$. Die Beweislast für mangelnde Kausalität hat der Versicherungsnehmer; er muß den Beweis strikt führen. ${ }^{15} \ldots$ Mitverursachung genügt zur Verwirkung. ${ }^{16}$ Die geringste Kausalität führt zur vollen Verwirkung (gemäßigtes Alles-oder-nichts-Prinzip). b) Obliegenheiten nach Eintritt des Versicherungsfalls, III: Hier bleibt bei grob fahrlässigem Verstoß der Versicherer insoweit verpflichtet, als die Verletzung weder Einfluß auf die Feststellung des Versicherungsfalls noch auf die Feststellung oder den Umfang der dem Versicherer obliegenden Leistung gehabt hat (Kausalitätsprinzip). “

Verständlich wird diese Neukommentierung, wenn man sich klar macht, daß $\S 6$ VVG mit Wirkung 1. Juli 1940 neu gefaßt worden war. Bei Obliegenheitsverletzungen vor dem Versicherungsfall konnte sich der Versicherer nur noch auf Leistungsfreiheit berufen, wenn er kündigte und bei Verstoß gegen eine nach dem Versicherungsfall zu erfüllende Obliegenheit wurde das Kausalitätserfordernis bei grobfahrlässigen Obliegenheitsverletzungen eingeführt. Prölss schreibt dann auch, daß die neue am $\S 32$ des österreichischen VVG angelegte Fassung, die Lage des Versicherungsnehmers nicht unbeträchtlich verbessere. ${ }^{17}$

Am Wortlaut der Kommentierung ändert sich, bis auf einige Nachweise, viele Jahrzehnte nichts. Allerdings stellt der BGH 1952 klar, daß das Alles-oder-nichtsPrinzip bei vorsätzlicher Verletzung von Obliegenheiten nach dem Versicherungsfall uneingeschränkt gilt. ${ }^{18}$ Der Österreichische Oberste Gerichtshof stimmt dem BGH uneingeschränkt zu. ${ }^{19}$ Prölss verweist auf die Fahrerflucht-Urteile, und betont, daß es nicht darauf ankommt, ob es sich um eine für den Versicherer wesentliche Obliegenheit handelt. ${ }^{20}$

Die Vielzahl der BGH-Entscheidungen zeigt allerdings, daß bei den Betroffenen große Unruhe herrscht. Das OLG Karlsruhe entscheidet im Jahre 1960 erstmals, daß ,,auch bei vorsätzlichen Verstößen gegenüber der Leistungsfreiheit der

${ }^{14}$ RGZ 157, 67; 160, 3.

15 Verkannt von RG VU 23 Nr. 1347.

16 Vgl. RG VU 25 Nr. 1499.

17 2. Auflage 1940, § 6 Ziff. 1.

18 BGH VersR 1952, 428; 56, 485; 58, 389; 60, 1033; 62, 501.

19 VersR 1965, 170.

20 15. Auflage 1965, § 6 Ziff. 9. 
Einwand der Arglist möglich sei“ ${ }^{21}$ Erich R. Prölss nimmt nur indirekt Stellung und wiederholt seinen Satz, der schon in der 4. Auflage gestanden hat: „Die geringste Kausalität führt zur vollen Verwirkung (gemäßigtes Alles-oder-nichts-Prinzip).“ Außerdem kann er den BGH mit einer Entscheidung aus dem Jahre 1964 für diese strikte Auffassung zitieren. ${ }^{22}$

Bei den Obliegenheitsverletzungen nach Eintritt des Versicherungsfalles gilt bei grob fahrlässigen Pflichtverletzungen das Kausalitätsprinzip. Folglich kommt es darauf an, ob das Verhalten des Versicherungsnehmers entweder keinen Einfluß auf die Feststellung oder keinen Einfluß auf den Umfang der den Versicherer obliegenden Leistung gehabt hat. Ein Einfluß auf die Feststellung der dem Versicherer obliegenden Leistung liegt nach Meinung des $B G H$ bereits dann vor, wenn der Versicherungsnehmer das in den Allgemeinen Versicherungsbedingungen vorgesehene oder in der Praxis übliche Feststellungsverfahren - oder ein diesem gleichwertiges - unmöglich gemacht hat. ${ }^{23}$ Jede längere Verzögerung der Schadensanzeige ist in diesem Sinne kausal, da ein längerer Zeitablauf im allgemeinen die Möglichkeit verringert, die Ursache eines Schadensvorganges festzustellen. ${ }^{24}$

Diese Rechtsprechung führt letztlich dazu, das Kausalitätsprinzip ins Gegenteil zu verkehren. Es wird nicht mehr darauf abgestellt, ob die Feststellung eines Schadens konkret beeinflußt wurde - es reicht bereits die Möglichkeit aus. Damit hat man im Bereich der groben Fahrlässigkeit das Kausalitätserfordernis praktisch eliminiert und das Alles-oder-nichts-Prinzip im Ergebnis wieder hergestellt. Diese Urteile ergehen Ende der fünfziger, Anfang der sechziger Jahre des letzten Jahrhunderts - der Zweite Weltkrieg und der Zusammenbruch des Nazi-Reiches liegen fast zwanzig Jahre zurück. Die Entscheidungspraxis zum Alles-oder-nichtsPrinzip legt einen restaurativen, begriffsjuristisch starren Geist offen, dem es nicht um die Funktionen und den Zweck des Rechts, sondern offenbar darum geht, mit der Knute des Rechtsstaates jeden zu treffen, der es wagt, eine sanktionsbewehrte Pflicht zu verletzen. Der Rechtsstaat pervertiert sich in diesen Urteilen selbst. Das Prinzip der Verhältnismäßigkeit und des Funktionsbezugs des Rechts wird durch Befehl und Gehorsam ersetzt - das Ganze erinnert an den „Untertan“ von Heinrich Mann.

Die Wende liegt aber in der Luft. Vor allem die Rechtsprechung der Oberlandesgerichte zeigt dies an. Das OLG Koblenz ${ }^{25}$ schränkt das Alles-oder-nichtsPrinzip erstmals ein. Es folgen das OLG Karlsruhe ${ }^{26}$ und das OLG Düsseldorf ${ }^{27}$. Schließlich fällt der BGH am 16. Oktober 1968 ein folgenschweres Grundsatzurteil. Ein mit Heizöl gefüllter Tanklastwagen durchfährt am 1. April 1961 auf

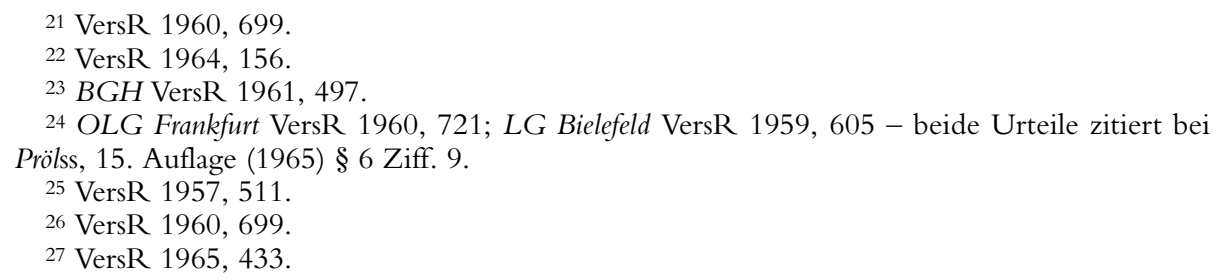


einer Bundesstraße eine Rechtskurve. Kurze Zeit darauf ereignet sich dort ein schwerer Verkehrsunfall. Ein Pkw gerät auf einer dünnen Ölschicht, die die Straße in einer Länge von etwa 70 bis 100 Meter bedeckt, ins Schleudern und fährt frontal gegen einen Straßenbaum. Alle Fahrzeuginsassen, vier Erwachsene und zwei Kinder, werden verletzt. Der Kraftwagen wird vollständig zertrümmert.

Nach den polizeilichen Ermittlungen stammt der Ölfilm aus einem undichten Verbindungsflansch des Tanklastwagens. Der Versicherer lehnt die Gewährung von Versicherungsschutz ab, weil der Versicherungsnehmer durch die Benutzung des Tankwagens in einem mangelhaften Zustand eine Gefahrerhöhung vorgenommen und außerdem seine Aufklärungspflicht durch unrichtige Angaben verletzt habe.

Das Berufungsgericht warf dem Versicherungsnehmer vor, daß diese Angaben objektiv falsch gewesen seien. Vielmehr hätten der Versicherungsnehmer und sein Sohn bei der Untersuchung des Wagens eindeutig festgestellt, daß vom Fahrzeug Heizöl auf die Straße getropft sei.

Der $B G H$ stellt klar, daß das Berufungsgericht zunächst einmal hätte klären müssen, ob der Versicherungsnehmer über den Rechtsverlust, der ihm bei bewusst falschen Schadensangaben drohe, belehrt worden sei. Sei der Versicherungsnehmer auf die Rechtsfolge falscher Angaben nicht hingewiesen worden, so sei der Versicherer zur Leistung insoweit verpflichtet geblieben, als die Verletzung der Auskunftspflicht weder die Feststellung des Versicherungsfalls noch die Feststellung oder den Umfang der den Versicherer obliegenden Leistung beeinflußt habe.

Bei vorheriger Belehrung des Versicherungsnehmers wäre der Versicherer hingegen auch dann in vollem Umfang leistungsfrei geworden, wenn ihm die falschen Angaben keinerlei Nachteile gebracht hätten.

Diesen eher milden Tönen läßt der BGH dann aber doch einige Grundsätze folgen, die klar machen, daß ihm und allen Beteiligten völlig klar ist, worum es immer gegangen ist und auch gehen soll. Das Berufungsgericht hatte nämlich darauf abgestellt, daß der Umfang der Anspruchsverwirkung der Schwere der Obliegenheitsverletzung nach Verschulden und Auswirkungen angemessen sein müsse. Damit hat das OLG Oldenburg bereits im Jahre 1967 das von der VVG-Reformkommission im Jahre 2004 empfohlene Quotensystem vorweggenommen. Der $B G H$ hielt dagegen, ,daß der volle Anspruchsverlust, den der $\S 6$ Abs. 3 VVG bei vorsätzlichem Verstoß vorschreibt, weder dem Verschulden, noch den Auswirkungen der Obliegenheitsverletzung angemessen $\mathrm{zu}$ sein braucht, sondern darüber erheblich hinausgehen kann. Diese Regelung hat ihren Grund in dem damit verfolgten Präventionszweck. Die darin im Regelfall liegende Härte sei vom Gesetz beabsichtigt und reiche deshalb für sich allein nicht aus, um die bindende Norm des $\S 6$ Abs. 3 VVG nicht anwenden zu müssen, sondern statt dessen eine nach Treu und Glauben billige und angemessene Teilverwirkung festsetzen zu können. ${ }^{28}$

Worum war es in Wirklichkeit gegangen? In Wirklichkeit ging es um einen völlig nichtssagenden und überflüssigen Passus in einem Brief des Versicherungsnehmers an seinen Versicherer. Der Versicherungsnehmer meinte, es könne Wasser

${ }_{28}$ BGH VersR 1968, 1155, 1157. 
gewesen sein, das von der Pritsche tropfte, weil es stark regnete. Er und sein Sohn wussten aber, daß es Heizöl war und das hatten sie auch der Polizei gegenüber eingestanden. Der Versicherer konnte also bei einem Blick in die polizeiliche Ermittlungsakte sofort erkennen, dass die undichte Stelle beim Tankwagen die eigentliche Unfallursache war. Warum der Versicherungsnehmer selbst zunächst gegenüber der Polizei die Wahrheit sagte und dann später gegenüber dem Versicherer versucht, so zu tun, als sei ihm die Unfallursache nicht ganz klar, bleibt im dunkeln. Möglicherweise fürchtet er auch - ganz unbegründet - um seinen Versicherungsschutz. Aber nun, durch diese kleine Notlüge, die sofort entdeckt wird, fällt der Hammer der Justiz mit voller Wucht auf ihn nieder. Und das, obwohl dem Versicherer weder bei der Feststellung noch beim Umfang des Versicherungsfalles irgendein Nachteil entstanden ist.

Jürgen Prölss, der inzwischen die Kommentierung von $§ 6$ VVG übernommen hat ${ }^{29}$, assistiert: „Der Versicherer ist (anders als andere Vertragspartner) vor vorsätzlichen Pflichtverstößen nicht genügend geschützt, sofern der Versicherungsnehmer nur belangt werden kann, wenn und soweit hierdurch Nachteile verursacht werden. Entgegen Kramer ${ }^{30}$ bietet - von den Fällen der Unfallflucht abgesehen $(§ 7$ AKB, Anm. 2) - auch das Strafrecht keine hinreichende Prävention: Häufig erfüllen vorsätzliche Pflichtverstöße von vornherein keinen Straftatbestand; wo § 263 StGB in Betracht kommt, ist der Nachweis des Schädigungsvorsatzes und der Bereicherungsabsicht oft schwierig. ,Auch eine teilweise Herabsetzung des Deckungsanspruchs durch Richterspruch analog $\S 343$ BGB ist de lege lata nicht möglich (BGH VersR 72, 363, h.M.; a.A. OLG Koblenz VersR 72, 921). Dies widerspricht dem Gesetz und führt mangels hinreichend bestimmter Kriterien zu einer erheblichen Rechtsunsicherheit, die wegen ihrer Folgen für den Rechtsverkehr nicht mit ähnlichen Schwierigkeiten bei der Strafzumessung verglichen und unter Berufung hierauf hingenommen werden kann. " ${ }^{31}$

Die entscheidenden Fragen werden also gestellt und auch in ihren Konsequenzen voll erkannt. Es wird gesehen, daß vorsätzliche Pflichtverstöße geeignet sein müssen, die ,Versichertengemeinschaft zu treffen“. Ein folgenlos bleibender Pflichtverstoß trifft aber die Versichertengemeinschaft nicht - er ist ja folgenlos. So gesehen bedürfte es des Umwegs über $§ 343$ BGB analog, den das OLG Koblenz vorschlägt, gar nicht. Es reicht schon festzustellen, daß der Zweck des $§ 6$ Abs. 3 VVG selbst seine generalpräventive Wirkung jedenfalls dann nicht entfalten kann, wenn der Pflichtenverstoß im Einzelfall folgenlos bleibt. Verweigert man dem Versicherungsnehmer in diesen Fällen dennoch die Leistung, so verändert man den generalpräventiven Zweck des $§ 6$ Abs. 3 VVG in ein „Du sollst nicht lügen“. Und genau besehen, zeigt auch die Diskussion bis heute, daß es um dieses tief in uns verwurzelte achte Gebot des alten Testaments geht. ${ }^{32}$ Die Tatsache, daß unsere Strafgesetzbücher die bloße Lüge nicht unter Strafe stellen, wendet sich in $\S 6$ Abs. 3 VVG in fast tragischer Weise gegen den Versicherungsnehmer. Weil das

29 19. Auflage, 1973.

${ }^{30}$ NJW 1972, 1974.

31 Jürgen Prölss, VVG-Kommentar 19. Auflage, 1963, § 6 B aa am Ende.

32 2. Buch Moses Kap. 20: „Du sollst nicht falsch Zeugnis reden wider deinen Nächsten“. 
Strafgesetzbuch ihn nicht behelligt, muß er jetzt durch eine zivilrechtliche Norm zur Ordnung gerufen werden - dabei werden dann die Grundprinzipien des Strafrechts, nämlich die Angemessenheit zwischen Schuld und Strafe außer Kraft gesetzt.

In den Jahren nach 1968 hat dann aber doch der BGH das entwickelt, was wir heute Relevanzrechtsprechung nennen. ${ }^{33}$ Nach dieser Rechtsprechung kann aus einer vorsätzlichen Verletzung der Obliegenheit, die tatsächlich ohne jede Relevanz für den Versicherer war, ein Recht zur Leistungsverweigerung nicht hergeleitet werden. Der Versicherer kann sich in den Fällen, in denen eine vorsätzliche Obliegenheitsverletzung folgenlos geblieben ist, auf die vereinbarte Leistungsfreiheit nur berufen, wenn der Obliegenheitsverstoß

- objektiv, d.h. generell, geeignet war, die Interessen des Versicherers ernsthaft zu gefährden und

- subjektiv von einigem Gewicht war, d.h. den Versicherungsnehmer ein erhebliches Verschulden trifft.

Bei Auskunftsobliegenheiten verlangt die Rechtsprechung bereits seit 1964, daß der Versicherungsnehmer über den möglichen Verlust eines Anspruchs belehrt worden ist.

Die VVG-Reformkommission empfiehlt heute nichts anderes als das, was in der Relevanzrechtsprechung angelegt ist, nämlich eine Berücksichtigung der Schwere der Obliegenheitsverletzung nach Verschulden und Auswirkung im Einzelfall. Das gleiche hat bereits das OLG Oldenburg im Jahre 1967 gefordert.

In diesem Sinne beginnt sich die Kommentierung bei Jürgen Prölss in der 20. Auflage (1975) zu wandeln. Dort schreibt er, daß die Leistungsfreiheit bei folgenlosen Verstößen durch den Präventions- und Garantiezweck der Verwirkungsabrede gedeckt sein müsse. ${ }^{34}$ Aber noch in der 27. Auflage aus dem Jahre 2004 führt Jürgen Prölss fort: „Somit besteht ein besonderes Bedürfnis des Versicherers nach einer Prävention vorsätzlicher Obliegenheitsverstöße." Diesem würde bei Geltung des Kausalitätsprinzips nicht hinreichend Rechnung getragen werden, da dann die Abschreckungswirkung wegen der häufig gegebenen Risikolosigkeit vorsätzlicher Verstöße erheblich gemindert wäre, was auch - der hier vertretenen Optimierungsaufgabe der Versicherung widersprechende - Konsequenzen für das Risikokollektiv hätte.

Das stimmt natürlich, aber immer nur dann, wenn die Pflichtverletzung des Versicherungsnehmers wirtschaftliche Nachteile für den Versicherer bewirkt. Deshalb wird die Diskussion um das Alles-oder-nichts-Prinzip wohl doch den „Strich des Gesetzgebers“ benötigen, der dann die Literatur und Rechtsprechung eines ganzen Jahrhunderts zu dieser Frage zu „Makulatur“ machen wird. Sollte der Gesetzgeber im Jahre 2008 diesen Strich getan haben, so sollten wir aber nie vergessen, wie lange wir gebraucht haben, ernsthafte, vernünftige und hochintelligente Menschen zu der Einsicht zu bringen, daß das Zivilrecht nicht dazu mißbraucht werden darf, Lügen zu bestrafen, die nach dem Strafrecht nicht strafbar sind.

33 Erstmals BGH VersR 1969, $651=$ NJW 1969, 1385.

$34 \S 6 \mathrm{C}$ a. 


\section{Gegenwart}

Das Programm des C.H. Beck-Verlages von 1905 bis 1935 umfaßt im Privatversicherungsrecht gerade einmal sieben Titel. Von 1935 - die Ära Prölss beginnt bis 1968 sind es ca. 30 Titel, die meisten davon aus der Feder von Erich R. Prölss. 70 Jahre Verlagsgeschichte passen auf einen zweiseitigen Ausdruck. Mit dem Jahr 1970 wird - nicht nur, aber auch - im Privatversicherungsrecht eine völlig neue Ära eingeläutet. Die wissenschaftliche und praktische Durchdringung des Gebietes verstärkt sich geradezu exponentiell. 30 Jahre nach Kriegsende beginnen die Wunden, die die Nazis der Privatversicherungswissenschaft angetan haben, ganz langsam zu verheilen - an die Stelle der großen Arbeiten von Julius von Gierke, Alfred Manes, Viktor Ehrenberg, Albert Ehrenzweig, W. Lewis treten im C. H. Beck-Verlag neuere, moderne Werke. ${ }^{35}$

$\mathrm{Ob}$ die Ursache für diese Zeitenwende auf dem Markt für privatversicherungswissenschaftliche Literatur allein im Zweiten Weltkrieg zu suchen und zu finden ist, werden genauere historisch-analytische Untersuchungen zu zeigen haben. Das Bevölkerungswachstum könnte eine Mitursache sein - der geburtenreichste Jahrgang, den die Bundesrepublik je erlebt hat, war das Jahr 1964. Aber das alles genügt wahrscheinlich nicht, um diese geradezu explosionsartige Entwicklung der wissenschaftlichen Literatur im C. H. Beck-Verlag nachvollziehen zu können. Eine ganz wichtige Mitursache dürfte der Übergang von der Arbeitsgesellschaft zur Informations- und Wissensgesellschaft Anfang der siebziger Jahre des letzten Jahrhunderts sein. Äußerer Ausdruck war die Öffnung der Universitäten unter dem Stichwort Chancengleichheit für alle. Während noch Mitte der 60er Jahre etwa 4\% eines Jahrgangs einen Universitätsabschluß anstrebten, erhöhte sich dieser Prozentsatz Mitte der siebziger Jahre auf 20\% bis 25\%.

Von alledem ist im Jahre 1970 noch nicht allzu viel zu spüren. Jürgen Prölss tritt in die Fußstapfen des Vaters und führt zusammen mit dem genialen, aber viel zu früh verstorbenen Anton Martin den VVG-Kommentar fort. Es erscheint die 18. Auflage. Reimer/Schmidt und Jürgen Sasse übernehmen das Versicherungsaufsichtgesetz und veröffentlichen im Jahre 1971 die 6. Auflage, Anton Martin einen Kommentar zur Montageversicherung im Jahre 1972 und dann - wir sind im Jahre 1976 - geht es Schlag auf Schlag. Von Günther Bauer erscheint die Kraftfahrtversicherung, von Günther Schaub die betriebliche Altersversorgung. Die Versicherungsbetriebslehre meldet sich im Jahre 1977 mit Elmar Helten zu Wort. Das erste studentische Lehrbuch erscheint im Jahre 1978 von Edgar Hofmann, die Rechtsschutzversicherung von Walther Harbauer im Jahre 1980, die gesetzliche Unfallver-

\footnotetext{
${ }^{35}$ Sie verbinden sich mit den Namen Anton Martin, Reimer/Schmidt, Jürgen Sasse, Günther Bauer, Günther Schaub, Friedrich Aichberger, Elmar Helten, Edgar Hofmann, Walther Harbauer, Jochen Plagemann, Peter Bach, Ernst C. Stiefel, Horst K. Jannott, Wolfgang Grimm, Gert Andreas Benkel, Heinrich Dörner, Detlef Kaulbach, Peter Frey, Hubert Willhelm van Bühren, Walther Hempfing, Bernd Späte, Wolfgang Voit, Ulrich Fahr, Hans Jürgen Wussow, Helmut Müller, Dirk E. Meyer-Scharenberg, Wolfgang Römer, Theo Langheid, Hans Feyock, Peter Jacobsen, Ulf Lemor, Peter Präve, Dieter Budde, Peter Schimikowski, Guido Holzhauser, Jürgen Prölss, Ulrich Knappmann, Helmut Kollhosser, Christian Armbrüster, Roland M. Beckmann und Michael Terbille - ohne daß diese Liste von Autoren, die seit 1970 im Verlag C. H. Beck veröffentlich haben, vollständig wäre.
} 
sicherung von Jochen Plagemann 1981. Das bis heute unübertroffene Sachversicherungsrecht von Anton Martin kommt im Jahre 1982. Peter Bach und Hans Moser schreiben den Kommentar zur privaten Krankenversicherung 1984. Der Kommentar zur Kraftfahrtversicherung von Ernst C. Stiefel und Edgar Hofmann erscheint 1986 bereits in der 13. Auflage. Wolfgang Grimm legt den Kommentar zu den Allgemeinen Unfallversicherungsbedingungen 1987 vor. Das Werk von Benkel und Hirschberg zu Berufsunfähigkeit und Lebensversicherung erscheint 1990. Die durch das Dienstleistungsurteil des Europäischen Gerichtshofs im Jahre 1986 ausgelöste Diskussion um die Öffnung der Versicherungsmärkte ${ }^{36}$ führt bei Reimer Schmidt zu juristischen Überlegungen zur Deregulierung des Versicherungsrechts im Jahre 1991. Und 1994 - die Marktöffnung erzwingt ein völlig neues Denken im Bundesaufsichtsamt für das Versicherungswesen (heute BaFin) - erscheint der erste Kurz-Kommentar zum VAG von Ulrich Fahr und Detlef Kaulbach. Der Zeitenwechsel auf den Deutschen Versicherungsmärkten ist mit Händen zu greifen.

Der Präsident des BAV, Helmut Müller, tritt mit einer richtungsweisenden Schrift zum Versicherungsbinnenmarkt und zur europäischen Integration im Versicherungswesen an die Öffentlichkeit - wir haben das Jahr 1995. Im C. H. Beck-Verlag wird eine neue Verlagspolitik verfolgt. Neben die früheren Kurz-Kommentare, die sich wie beim VVG und VAG inzwischen zu honorigen, auf Dünndruckpapier erscheinenden „Dickschiffen“ verändert haben, tritt die Generation der kleinen handlichen orangefarbenden Kommentare. Im Privatversicherungsrecht gelingt dem C.H. Beck-Verlag ein Meilenstein - der „Römer/Langheid“ erscheint 1997. Wolfgang Römer, der engagierte, charismatische und durchsetzungsfähige Vorsitzende des IV. Senats beim BGH präsentiert zusammen mit Theo Langheid, dem brillanten und bekanntesten deutschen Versicherungsanwalt, einen VVG-Kommentar, der - so wie die erste Auflage des „Prölss“ im Jahre 1935 - von allem Ballast befreit ist und die Dinge knapp, kurz, prägnant und zielführend auf dem Punkt bringt. Der „Römer/Langheid“ ist schon kurz nach seinem Erscheinen aus den Taschen der Versicherungsjuristen und den Regalen der Bibliotheken nicht mehr wegzudenken. Das gleiche gilt für das Parallelwerk von Fahr/Kaulbach zum VAG.

Von nun an gibt es jährlich mehr Neuerscheinungen als in den dreißiger und vierziger Jahren pro Jahrzehnt. Vorbildlich ist der Kommentar zur Kraftfahrtversicherung von Feyock, Jacobson und Lemor aus dem Jahre 1997. Das Gleiche gilt für die Arbeit von Peter Präve zu Versicherungsbedingungen und AGB-Gesetz, ebenfalls 1997, und die Haftpflichtversicherung im privaten und gewerblichen Bereich von Michael F. Bengler. Aus der Feder von Meier/Biela erscheint 1998 die Kaskoversicherung. Dann erscheint - erstmals und von großer Bedeutung - der Beck'sche Versicherungsbilanz-Kommentar, herausgegeben von Wolfgang Dieter Bude 1998. Lehrbücher von Guido Holzhauser und Peter Schimikowski zum Versicherungsvertragsrecht reichern das Programm 1999 an. Tradiert ist inzwischen die Textausgabe der Allgemeinen Versicherungsbedingungen von Heinrich Dörner, ebenso wie der Unfallversicherungskommentar von Wolfgang Grimm, der in der 3. Auflage 2000

36 Dazu umfassend Schwintowski, Der private Versicherungsvertrag zwischen Recht und Markt, 1987, ab S. 241. 
erscheint. Siegurd Littbarski kommt im Jahr 2000 mit der Produkthaftpflichtversicherung und im Jahr 2001 mit einem AHB-Kommentar auf den Markt und Detlef Kröger zeigt im Jahre 2003 Internetstrategien für Versicherungen - das Internetrecht hat die Versicherungswirtschaft erreicht. Im Jahre 2004 stößt Christian Armbrüster zum Team des inzwischen altehrwürdigen VVG-Kommentars von Prölss. Zu dieser Zeit weiß noch niemand, dass Helmut Kollhosser kurze Zeit später - Anfang 2005 - einer schweren Krankheit erliegen wird. Damit werden viele Aufgaben, die er sich noch vorgenommen hatte - insbesondere die Neuherausgabe des großen VAG-Kommentars - in eine ungewisse Zukunft verschoben.

Gleichzeitig bahnt sich eine neue Generation von Verlagserzeugnissen ihren Weg. Das von Beckmann/Matusche-Beckmann herausgegebene Versicherungsrechtshandbuch erscheint im Jahre 2004. Mit an Deck sind die Altmeister des Versicherungsrechts, wie Egon Lorenz, Heinrich Dörner, Wulf-Henning Roth, Ulrich Knappmann oder Helmut Müller, aber auch die jüngere Professorengeneration, wie Manfred Wandt, Peter Reiff, Harald Herrmann oder Peter Heiss, ist dabei und hinzu kommen die ganz Jungen, die in Zukunft die Geschicke im Versicherungsrecht in den Händen halten werden, wie Christoph Brömmelmeyer oder Jacob Joussen. Nahezu zeitgleich erscheint das Münchener Anwalts-Handbuch Versicherungsrecht, herausgegeben von Michael Terbille. Dies zeugt nicht nur von einem völlig neuen Selbstverständnis, sondern vor allem auch davon, daß sich den Anwälten ein neues Arbeitsfeld öffnet. Die Deregulierung zeigt ihre Wirkungen. Marktfreiheiten führen nicht nur zu größeren Chancen, sondern auch zu größeren Risiken und Konflikten. Der Beratungsbedarf im Privatversicherungsrecht hat erheblich zugenommen. Unternehmen können neue Versicherungsprodukte weitgehend nach eigenen Vorstellungen entwickeln und gestalten. Dies löst enormen juristischen Beratungsbedarf innerhalb der Unternehmen aus. Die Umsetzung der Vermittlerrichtlinie im Jahr 2005 wirft ihre Schatten voraus. Erstmals werden die Vermittler spezifische Beratungs- und Dokumentationspflichten zu erfüllen haben. Sie werden darüber hinaus in einem gewerberechtlichen Register geführt werden das Qualifikationsniveau wird auf den Prüfstand gestellt werden. Auch hier entstehen Rechtsfragen, die es in regulierten Zeiten nicht gegeben hat.

Schließlich hat die Justizministerin (Herta Däubler-Gmelin) im Jahre 2000 einer Gruppe von etwa 20 Wissenschaftlern, Praktikern und Richtern den Auftrag erteilt, das altehrwürdige, aber in die Jahre gekommene VVG zu reformieren. Die VVG-Reformkommission hat im April 2004 den Vorschlag für ein neues VVG mit Begründung auf den Tisch gelegt und allgemein wird damit gerechnet, daß ein neues VVG im Jahre 2008 in Kraft treten wird. Die Dynamik im Privatversicherungsrecht ist hoch und ungebremst, eine Tatsache, die dazu führen wird, daß das Verlagsprogramm des C.H. Beck-Verlages in diesem Bereich eher noch schneller wachsen wird, als wir dies in den vergangenen 15 Jahren erlebt haben. 


\section{B. Bankrecht}

\section{Entwicklung bis heute}

Im Bankrecht stellen sich die Dinge völlig anders dar als im Privatversicherungsrecht. Das hat zunächst damit zu tun, daß es das Bankrecht als Rechtsgebiet überhaupt erst seit dem Ende der siebziger Jahre des vergangenen Jahrhunderts gibt. Man differenziert gewöhnlich zwischen dem allgemeinen klassischen Bankrecht, das das Einlagengeschäft, das Kreditgeschäft und den Zahlungsverkehr jeweils mit Nebenauswirkungen umfaßt (Commercial Banking). Daneben steht das wertpapierbezogene Geschäft, das Investmentbanking. Hier geht es um Vermögensverwaltung, Finanzinnovationen und das Immissions- und Konsortialgeschäft. Aber bis heute ist nicht wirklich klar, welche Rechtsmaterien wirklich zum Bankrecht zählen. Gehört etwa das Börsenrecht dazu oder das Investmentrecht? Ist das Wertpapierhandelsgesetz Teil des Bankrechts oder des Kapitalmarktrechts - oder läßt sich beides nicht sinnvoll voneinander trennen? Wie ist es mit dem Wertpapierübernahmegesetz, dem es im Kern doch um die Übernahme von Unternehmen am Kapitalmarkt geht? Hat das nicht mehr mit dem Unternehmenskauf und weniger mit dem Bankrecht zu tun?

Diese Abgrenzungs- und Einordnungsschwierigkeiten haben zunächst ganz schlicht damit zu tun, daß es ein Bankgesetzbuch im Gegensatz zum Versicherungsvertragsgesetz nicht gibt. Umgekehrt gibt es keinerlei Schwierigkeiten auf der aufsichtsrechtlichen Seite. Wir haben seit langem ein Kreditwesengesetz und niemand zweifelt daran, daß dieses die Aufsicht über die Banken beinhaltet.

So gesehen gibt es ein Verlagsprogramm des C. H. Beck-Verlags zum Bankrecht erst in neuerer und neuester Zeit. Immerhin hat Adolf Baumbach in der Reihe, in der 1935 die erste Auflage des Prölsschen Kommentars zum Versicherungsvertragsgesetz erschien, zuvor die berühmte Kommentierung zum Handelsgesetzbuch veröffentlicht - die 1. Auflage erschien bereits im Jahre 1932. In diesem Werk war damals auch das Börsengesetz enthalten. So gesehen gibt es im Verlagsprogramm von C.H. Beck seit langem auch ein Stück Bankrecht. Mit der 25. Auflage des nunmehr von Hopt bearbeiteten Baumbach-Kommentars hat das Bankrecht einen besonders prägnanten Platz gefunden, da Hopt ihm unter dem Titel Bankgeschäfte erstmals erheblichen Kommentierungsraum gegeben hat. Aber heute findet man im Verlagskatalog von C.H. Beck den „Baumbach/Hopt“ (inzwischen 31. Auflage) natürlich nicht im Bank- und Kapitalmarktrecht, sondern im Bereich des Handelsrechts. Auch der 5. Band des 2001 erschienenen Münchener Kommentars zum HGB, der im wesentlichen das Recht des Zahlungsverkehrs, Effektengeschäfte und das Depotgeschäft enthält, wird im Handelsrecht präsentiert, beim Bank- und Kapitalmarktrecht aber nicht einmal erwähnt.

Das gilt natürlich auch für die vielfältigen bürgerlich-rechtlichen Kommentare, die im C.H. Beck-Verlag erscheinen. Der berühmteste BGB-Kommentar der Republik, der „Palandt“, heute in der 67. Auflage, enthielt natürlich von der ersten Auflage an auch Bankrecht, nämlich das Darlehensrecht, das Bürgschaftsrecht 
und das Recht der Schuldverschreibungen. Heute finden wir im BGB viel mehr, nämlich den Girovertrag, den Überweisungsvertrag, den Zahlungsvertrag, den Darlehensvertrag, das Verbraucherdarlehensrecht und das Recht der Schuldverschreibungen. Aber umgekehrt sind das Einlagengeschäft, die Kontoformen, das Lastschriftrecht, das Scheckgeschäft, das Recht der automatisierten Zahlungssysteme, das Kreditkartengeschäft ebenso wenig Teil des BGB, wie das Depotgeschäft oder die Vermögensverwaltung oder das Immissions- und Konsortialgeschäft.

Es ist also etwas schwierig mit dem Bankrecht, insbesondere dann, wenn man an das Kreditsicherheitenrecht denkt, das im wesentlichen im BGB steht. Es geht um Grundpfandrechte, Hypotheken, Factoring, Sicherungsübereignungen, Pfandrechte an beweglichen Sachen und Rechten und um Sicherungszessionen. Für Siegfried Kümpel, einen der profiliertesten Bankrechtler unserer Republik, gehört das Investmentrecht ebenso wie das Wertpapierhandelsgesetz und das Börsenrecht zum Bankrecht. Aber auch die staatliche Marktaufsicht und das Europäische System der Zentralbanken sind aus seiner Sicht Teile des Bank- und Kapitalmarktrechtes. Teile der Literatur definieren Bankrecht heute in einem funktionalen Sinne. Gemeint sind danach das Recht der Geldschöpfung, der Geldvernichtung, des Geldumlaufs, der Geldaufbewahrung und der Geldanlage. ${ }^{37}$ So gesehen ist Bankrecht ein extrem großes und weites Rechtsgebiet mit Bezügen zu einer Vielzahl von Institutionen innerhalb unseres Rechtssystems, ohne daß diese Institutionen im Einzelfall auf den Begriff Bank- oder Kapitalmarktrecht verweisen.

Das Programm des C.H. Beck-Verlages geht mit Einordnungsschwierigkeiten dieser Art so pragmatisch um, wie dies einem Verlag gebührt. Bank- und Kapitalmarktrecht ist das, was die Praxis so nennt. So findet man ein breites Spektrum an Veröffentlichungen unter den Stichworten Wertpapier-, Bank-, Börsen- und Kapitalmarktrecht. Besonderes Gewicht haben die von Nobert Horn und Klaus Peter Berger herausgegebenen bank- und kapitalmarktrechtlichen Schriften des Instituts für Bankrecht in Köln. Klassiker ist das Wechsel- und Scheckgesetz von Baumbach/Hefermehl in der 22. Auflage, die letzte von Hefermehl bearbeitete Auflage. Zunehmendes Gewicht gewinnt die Zeitschrift für Bank- und Kapitalmarktrecht. Unentbehrlich ist die Loseblatt-Textsammlung zum Kreditwesengesetz, herausgegeben von Consbruch/Möller/Bähre/Schneider. Der Kommentar zum Kreditwesengesetz vom Boos/Fischer/Schulte-Mattler, der in der 2. Auflage im Jahre 2004 erschienen ist, wird langsam zum Klassiker. Das kann man schon heute vom Kapitalmarktrechtskommentar, herausgegeben von Eberhard Schwark, sagen, der in der 3. Auflage ebenfalls im Jahre 2004 erschienen ist.

Im Mittelpunkt einer jeden Bankrechtsdiskussion steht aber das BankrechtsHandbuch, herausgegeben von Schimansky, Bunte und Lwowski. Rechtsgeschichte hat die erste Auflage geschrieben, die im Jahre 1997 erschien und sich sofort am Markt als Meinungsführer durchsetzte. 2001 ist die 2. Auflage des BankrechtsHandbuchs erschienen. Der besondere Erfolg des Handbuches beruht sicher auf der außergewöhnlichen Kompetenz derer, die an der Entstehung dieses Werkes beteiligt waren und sind. Dazu gehören praktisch geschlossen der Bankrechtssenat

37 Schwintowski/Schäfer, Bankrecht, 2. Auflage 2004, § 1 Rn. 2. 
des BGH, eine Vielzahl von hochqualifizierten Bankrechtlern aus den Universitäten, wie Hadding, Häuser, Hopt, Köndgen, Grundmann, Bunte oder Welter. Hinzu kommen brillante Bankrechtspraktiker wie etwa Bruchner, Eisele, Fischer, Rümker, Lwowski, Jahn, Janus, Merkel, Nielsen, Peters, Schefold, Steuer oder Troberg. Im Vorwort zur ersten Auflage heißt es: „Das Bankrecht ist als Rechtsgebiet nach Inhalt und Gegenstand nicht exakt festgelegt und schwer zu erfassen. Es stellt ein Konglomerat dar von öffentlich-rechtlichen Vorschriften, die zunehmend von der europäischen Rechtsangleichung im Bereich der Finanzdienstleistung beeinflußt werden, und von privat-rechtlichen Vorschriften, die das Bank-Privatrecht ausmachen. Das Bankrecht hat Berührungen und Überschneidungen mit einer großen Zahl von anderen Rechtsgebieten, dem Bürgerlichen Recht, dem Handelsrecht, dem Wertpapierrecht, dem Strafrecht, dem Steuerrecht, dem Verfahrensrecht und dem Staats- und Verwaltungsrecht. Den bankrechtlichen Bezug erhalten diese Rechtsgebiete dadurch, dass sie die Rechtsverhältnisse „der Banken“ regeln und berühren. Band 1 des auf drei Bände angelegten umfassenden Werkes enthält die allgemeinen Grundlagen, insbesondere das Recht der Allgemeinen Geschäftsbedingungen der deutschen Banken, die Bankgeschäfte mit Auslandsbezug, das Recht des Bankkontos, das Bankgeheimnis sowie Beratungs-, Warn- und Aufklärungspflichten der Bank auch im Zusammenhang mit Anlagevermittlung und Prospekthaftung. Den zweiten Abschnitt bildet der bargeldlose Zahlungsverkehr, insbesondere der Girovertrag und das Kontokorrent, die automatisierten Zahlungssysteme, das Lastschriftverfahren. Der Scheckverkehr, das Wechselgeschäft und das Kreditkartengeschäft schließen sich an.

Band II greift das Einlagen- und Kreditgeschäft auf. Dem Hypothekarkredit (Realkredit) wird großer Raum eingeräumt, ebenso wie dem Verbraucherkreditrecht. Band III enthält das Wertpapier-, Geld- und Auslandsgeschäft. Fremdwährungsschulden, Bankgeschäfte in fremder Währung und Devisenrecht werden ebenso abgehandelt wie einzelne Auslandsgeschäfte. Der Band wird mit dem Öffentlichen Bankrecht einschließlich der europarechtlichen Bezüge abgeschlossen. Dazu gehört das Recht der Bankenaufsicht sowie das Kartellrecht und die Beihilfenaufsicht.

Bankrecht ist heute ein boomende Materie. Die Veröffentlichungen im BeckVerlag sind - wie auch im Versicherungsrecht - prägend für den Gesamtmarkt, wenngleich daneben Werke entstanden sind, die das Angebot des C.H. BeckVerlages abrunden. Dazu zählt etwa das von Schwintowski und Schäfer verfaßte Standardwerk zum Bankrecht, das in der 2. Aufl. im Jahre 2003 im Carl Heymanns Verlag erschienen ist. Zu erwähnen ist aber auch das Handbuch zum deutschen und europäischen Bankrecht, herausgegeben von Derleder, Knops und Bamberger, erstmals im Jahre 2004 im Springer-Verlag erschienen. Daneben stehen die Standardwerke von Bülow zum Verbraucherkreditrecht und zum Wechsel, Scheckrecht und dem AGB-Recht der Banken, veröffentlicht im C.F. Müller-Verlag. Große Bedeutung hat der von Assmann und Schneider im Jahre 2003 in 3. Aufl. im Otto Schmidt Verlag herausgegebene Kommentar zum Wertpapierhandelsgesetz. Ebenfalls zur Standardliteratur zählt das Bank- und Kapitalmarktrecht von Kümpel und die von Kümpel, Hammen und Eckenga herausgegebene Loseblattsammlung 
zum Kapitalmarktrecht im Erich Schmidt Verlag. Das Kapitalanlagerecht wäre ohne das Handbuch von Assmann/Schütze, in der 2. Aufl. aus dem Jahre 1997 erschienen im C.H. Beck-Verlag, nicht denkbar. Das gilt auch für das große, von Hopt und Voigt herausgegebene Werk zur Prospekt- und Kapitalmarktinformationshaftung, erschienen im Jahre 2005 im Mohr Siebeck-Verlag.

Der Bundesgerichtshof hat das private Bankrecht als eigenständige Rechtsmaterie anerkannt, dergestalt, daß seit dem 1. Juli 1988 dem XI. Zivilsenat die wichtigsten Einzelbereiche des Bank-Privatrechts zur Zuständigkeit übertragen sind. Seitdem spricht die Fachwelt vom Bankrechtssenat des BGH.“

Dem ist nichts hinzuzufügen, außer dem Hinweis, daß das Bankrechts-Handbuch im Verlagsprogramm von einer Reihe ergänzender Kommentare und Monographien umgeben ist, die die führende Stellung des C.H. Beck-Verlages im Bereich des Bankrechtes dokumentieren. Zu nennen sind der Kommentar zum Wertpapiererwerbs- und Übernahmegesetz von Ehricke/Ekkenga/Oechsler, der Kommentar von Geibel/Süßmann ebenfalls zum WpÜG, das Handbuch zum Zahlungsverkehr von Langenbucher/Gößmann/Werner, das Handbuch zur Ad-HocPublizität von Möllers/Rotter, das Studienbuch von Claussen zum Bank- und Börsenrecht, der Kommentar von Brinkhaus/Scherer zum Gesetz der Kapitalanlagegesellschaften, das inzwischen zum Klassiker avancierte Handbuch des Kapitalanlagerechts von Assmann/Schütze oder das Handbuch zu Stock-Options vom Kessler/Sauter.

\section{Grenzen der Mithaftung für Darlehensschulden}

Im Jahre 1988 entschied das Landgericht Lübeck einen Fall, der Rechtsgeschichte machen sollte. ${ }^{38}$ Eine Friseurin, die noch in der Ausbildung war, hatte für den von ihrem Freund aufgenommenen Kredit zum Kauf eines Autos die Mithaftung übernommen. Der Kredit lautete auf 12300 DM und war in 36 Monatsraten zu 43 DM rückzahlbar. Der Freund verdiente zu jener Zeit 1500 DM pro Monat. Die junge Frau erhielt eine Ausbildungsvergütung in Höhe von 350 DM monatlich.

Das LG Lübeck hielt die Mithaftung für sittenwidrig (§ 138 BGB). Das Gericht rechnete vor, daß selbst nach Ablauf der Lehre bei einem zugrunde gelegten Nettoeinkommen der Frau von 800 DM monatlich der pfändungsfreie Betrag ab April 1984 lediglich 32 DM betragen hätte. Dagegen wären, wenn der Kredit notleidend geworden wäre, bereits monatliche Verzugszinsen in Höhe von 217 DM angefallen. Die F hätte sich somit in der Zwangslage befunden, entweder freiwillige Mehrleistungen zu erbringen und somit unter die Armutsgrenze zu geraten, oder aber sich - unter Umständen durch kriminelle Handlungen - weitere Mittel $\mathrm{zu}$ beschaffen.

Möglicherweise wäre dieses Urteil unbeachtet geblieben, wenn nicht das OLG Stuttgart am 12. Januar 1988 eine spektakuläre Analogie aus der Taufe gehoben hätte. Es handelte sich um das letzte Urteil unter dem Vorsitz des legendären

38 WM 1988, 966. 
Stuttgarter Richters Rolf Bender. Der Bender-Senat half mit einer Analogie zu dem bis dahin nahezu vergessenen $\S 310$ BGB a. F. (heute: $\S 311$ b Abs. 2 BGB): Wenn ein vermögensloser, auf künftiges Arbeitseinkommen angewiesener (Mit-) Schuldner sich zu Ratenzahlungen verpflichtet, die sein Existenzminimum aushöhlten, so sei diese Verpflichtung über künftiges Vermögen nach $\S 310$ BGB analog nichtig.

Der $B G H$, insbesondere der IX. Zivilsenat, war - unter seinem Vorsitzenden Merz - anderer Meinung. Er hielt dagegen, daß ein Volljähriger im allgemeinen auch ohne besondere Erfahrung in der Lage sei, zu erkennen, daß die Übernahme einer Bürgschaft ein riskantes Geschäft sei. ${ }^{39}$ Merz verwies auf das im Mittelalter geprägte und damals wie heute gefürchtete Sprichwort ,,wer bürgt, wird erwürgt“".

Die Urteile lösten eine der kontroversesten Diskussionen in der bankprivatrechtlichen Literatur aus. ${ }^{40}$ Letztlich war es aber der XI. Zivilsenat des BGH, der mit seinem Urteil vom 21. Januar 1991 die Dinge auf die Spitze trieb und aussprach, daß der Grundsatz der Privatautonomie nicht uneingeschränkt gelte und Generalklauseln wie $\S 138$ Abs. 1 BGB den Richter berechtigen und verpflichten, Rechtsgeschäfte, die nach allgemeinen Regeln wirksam erscheinen, aufgrund besonderer Umstände als nichtig zu bewerten. ${ }^{41}$ Demgegenüber beharrte der IX. Zivilsenat auf seiner Meinung und verurteilte eine längst geschiedene Frau für im Unternehmen ihres früheren Ehemannes entstandene Verbindlichkeiten in Höhe von fast DM 1 Mio. einzustehen, obwohl die Bedenken der Frau bei Unterschrift von ihrem Ehemann mit der Zusicherung zerstreut wurden, es gehe nur um ein bestimmtes Geschäft, bei dem „normalerweise nichts passieren könne“. Dem hatte der anwesende Mitarbeiter der Bank nicht widersprochen, obwohl die Bank selbst diese Einschätzung nicht teilte. ${ }^{42}$

Da beide Senate des BGH ihren Dissens nicht auflösten, wurde es Aufgabe des Bundesverfassungsgerichtes, den gordischen Knoten zu durchschlagen. ${ }^{43}$ Schon aus Gründen der Rechtssicherheit dürfe ein Vertrag nicht bei jeder Störung des Verhandlungsgleichgewichtes nachträglich in Frage gestellt oder korrigiert werden. Handele es sich jedoch um eine typisierbare Fallgestaltung, die eine strukturelle Unterlegenheit des einen Vertragsteils erkennen lasse, und seien die Folgen des Vertrages für den unterlegenen Vertragsteil ungewöhnlich belastend, so müsse die Zivilrechtsordnung darauf reagieren und Korrekturen ermöglichen. Das folge aus der grundrechtlichen Gewährleistung der Privatautonomie (Art. 2 Abs. 1 GG) und dem Sozialstaatsprinzip (Artt. 20 Abs. 1; 28 Abs. 1 GG). Für die Zivilgerichte folge daraus die Pflicht, bei der Auslegung und Anwendung der Generalklausel des $\S 138$ Abs. 1 BGB darauf zu achten, daß Verträge nicht als Mittel der Fremdbestimmung dienen.

39 BGH WM 1989, 245 = ZIP 1989, 219.

40 Überblick bei Schwintowski, ZBB 1989, 91; Medicus in: Aufklärungs- und Beratungspflichten der Kreditinstitute - der moderne Schuldturm; Schriftenreihe der Bankrechtlichen Vereinigung, Band III, S. 87; Köntgen NJW 1994, 1508, 1512.

${ }^{41}$ BGH WM 1991, 313, bestätigt durch BGH WM 1992, 2129.

42 BGH WM 1992, 391.

43 BVerfG NJW 1994, 36. 


\section{Versicherungs- und Bankrecht}

Ausgehend von diesen Grundsätzen hängt die Anwendung des $§ 138$ Abs. 1 BGB bei Bürgschafts- und Mithaftungsverträgen nach der inzwischen übereinstimmenden Rechtsprechung sowohl des IX. als auch des XI. Zivilsenates des $B G H$ regelmäßig vom Grad des Mißverhältnisses zwischen dem Verpflichtungsumfang und der finanziellen Leistungsfähigkeit des Bürgen ab. ${ }^{44}$

\section{Die Freigabe von revolvierenden Globalsicherungen}

Ein weiterer Diadochenkampf zwischen dem IX. und dem XI. Senat betraf revolvierende Globalsicherungen. Es ging um die Wirksamkeit formularmäßiger Globalabtretungen und Sicherungsübereignungen bei Warenlagern mit wechselnden Bestand. Jahrzehntelang hatten verschiedene Senate des BGH solche revolvierenden Globalsicherungen nur akzeptiert, wenn sie mit einer in bestimmter Weise formulierten Freigabeklausel verbunden waren.

Demgegenüber vertrat der Bankensenat, der XI. Zivilsenat, daß eine Globalabtretung trotz Fehlens einer ausdrücklichen, zahlenmäßig bestimmten Deckungsgrenze als wirksam anzusehen ist. Auf Vorlagebeschluß des IX. und des XI. Zivilsenates entschied schließlich der Große Zivilsenat des BGH am 27. November 1997 in dieser Frage und beendete damit einen Streit, der das Klima im BGH zu vergiften drohte und der von der Praxis eher mit Kopfschütteln begleitet wurde, weil der Streit im höchsten deutschen Zivilgericht zu einer fast zehnjährigen Rechtsunsicherheit beim Lieferantenkredit geführt hatte. Der Große Senat stellte zunächst klar, daß sich aus der Treuhandnatur des Sicherungsvertrages die Pflicht des Sicherungsnehmers ergibt, die Sicherheit schon vor Beendigung des Vertrags zurückzugewähren, wenn und soweit sie endgültig nicht mehr benötigt wird. Diese Pflicht folgt, so der Große Senat weiter, gem. § 157 BGB aus dem fiduziarischen Charakter der Sicherungsabrede sowie der Interessenlage der Vertragsparteien. ${ }^{45}$

\section{Heininger und die Folgen}

Der Heininger-Fall hat Bankrechtsgeschichte geschrieben und tut es noch. Die rechtliche Ausgangsfrage lautete schlicht, ob ein Realkreditvertrag, der in einer Haustürsituation geschlossen oder angebahnt wurde, widerrufen werden darf. Das ist eine harmlose Frage, deren Brisanz erst dann verständlich wird, wenn man sich vor Augen hält, daß Anfang und Mitte der 90er Jahre einige Banken versuchten, mit Hilfe von Strukturvertrieben, kreditfinanzierte Immobilien in großem Stil zu veräußern. Dabei wurden häufig auch (hohe) Vermittlungsprovisionen mitfinanziert. Dies blieb den Erwerbern in aller Regel verborgen. Nachdem im letzten Drittel der 90er Jahre die Euphorie auf den Immobilienmärkten verflog, offenbarte sich für viele Erwerber der Immobilienkauf nicht nur als Mißgriff, sondern als wirtschaftliches Desaster. Viele der erworbenen Objekte konnten nicht mehr oder nur $\mathrm{zu}$ sehr geringen Mieten vermietet werden. Die viel zu optimistisch erwarteten

${ }_{44}$ BGHZ 125, 206, 211; 136, 347, 351; 146, 37, 42.

45 NJW 1998, 671, 672. 
Steuervorteile fielen geringer oder sogar ganz (zum Beispiel bei Arbeitslosigkeit) aus. Da vielfach kleine Leute in den voll und ganz kreditfinanzierten Immobilienerwerb eingestiegen waren, hatten es die Banken plötzlich mit vielen Tausenden von Kunden zu tun, die die wirtschaftlichen Einbußen mit anderem Vermögen nicht abpuffern konnten. Der Erwerb der kreditfinanzierten Immobilie erwies sich für diese Investoren als mittel- und langfristig ruinös. Die Rechtsprechung konnte kaum helfen, weil bei steuersparenden Bauherren- und Erwerbermodellen die Trennungstheorie gilt. Das Kreditinstitut ist nur unter ganz besonderen Voraussetzungen zur Risikoaufklärung über das zu finanzierende Geschäft verpflichtet, weil regelmäßig davon auszugehen ist, daß die Kunden entweder selbst über die notwendigen Kenntnisse oder Erfahrungen verfügen oder daß sie sich jedenfalls der Hilfe von Fachleuten bedient haben ${ }^{46}$.

Der Europäische Gerichtshof antwortete am 13. Dezember 200147, er gehe davon aus, daß der zur Beurteilung anstehende Realkreditvertrag in einer Haustürsituation wurzele. ${ }^{48}$

Hieran anknüpfend hat der BGH am 9. April 2002 entschieden, daß $§ 5$ Abs. 2 HWiG (ab 1. Januar 2002: $§ 312$ a BGB) richtlinienkonform dahin auszulegen, daß dem Verbraucher, der einen in den Anwendungsbereich der Haustürrichtlinie fallenden Realkreditvertrag abgeschlossen hat, ein Art. 5 der Richtlinie entsprechendes Widerrufsrecht zusteht ${ }^{49}$.

Sollte danach ein Widerrufsrecht zu bejahen sein, so hat der BGH dem Berufungsgericht einige Hinweise mit Blick auf die Rechtsfolgen gegeben. Vor allem sei zu beachten, daß nach ständiger langjähriger Rechtsprechung mehrerer Senate des BGH Realkreditverträge und das finanzierte Grundstücksgeschäft grundsätzlich nicht als zu einer wirtschaftlichen Einheit verbundene Geschäfte anzusehen seien $^{50}$, denn bei einem Immobilienkauf weiß, so der Senat weiter, auch der rechtsunkundige und geschäftsunerfahrene Laie, daß Kreditgeber und Immobilienverkäufer in der Regel verschiedene Personen sind.

Diese Auffassung des XI. Zivilsenats hat den II. Zivilsenat des BGH allerdings nicht überzeugt. Er hat am 14. Juni 2004 entschieden, daß der Beitritt zu einem geschlossenen Immobilienfond und der Kreditvertrag zur Finanzierung dieses Beitritts durchaus ein verbundenes Geschäft sein können. Das gilt jedenfalls dann, wenn der Anleger beim Fondsbeitritt getäuscht worden ist.

Die Verwirrung schien eine Zeit lang komplett. Der XI. Zivilsenat des BGH meinte, kreditfinanzierte Immobilienkaufverträge seien keine verbundenen Ge-

46 BGH ZIP 2000, 1051, 1052; WM 1996, 1561 = WuB I G 7.-2. 87 v. Heymann, NJW-RR 1987, 523; Bruchner in: Bankrechts-Handbuch, 2. Aufl., Bd. 2, § 81 Rn. 15 e.

47 ZZB 2001, 29.

${ }^{48}$ EuGH ZBB 2002, $31 \mathrm{Tz} 25$.

${ }_{49}$ BGH NJW 2002, 1881, 1882f. mit ausführlicher Darstellung der hochkontroversen und ausufernden Literaturstimmen und Rechtsprechung zu den Möglichkeiten in einer weiten und engeren Auslegung des $\S 5$ Abs. $2 \mathrm{HWiG}$ - hierzu vgl. auch den Vorlagebeschluß des Senats NJW 2000, $521=$ WM 2000, 26, 27.

${ }^{50}$ BGH WM 1970, 1362, 1363; NJW 1980, 41 = WM 1979, 1054; NJW 1981, $389=$ WM 1980, 1446, 1447f.; NJW-RR 1987, 523 = WM 1986, 561, 562; NJW-RR 1992, 879 = WM 1992, 901, 905; NJW 2000, 3065 = WM 2000, 1287, 1288. 
schäfte - der II. Zivilsenat des BGH vertrat das Gegenteil. Im Frühsommer des Jahres 2006 hat es eine für den BGH ungewöhnlich Vereinbarung zwischen beiden Senaten gegeben. In Zukunft werden alle Fälle dieser Art einheitlich vom XI. Senat entschieden. Dieser hat seine Trennungstheorie im Urteil vom 16. 5. $2006^{51}$ bekräftigt. Er hat dann aber hinzugefügt, dass Anleger in Fällen eines institutionalisierten Zusammenwirkens der kreditgebenden Bank mit dem Verkäufer der Immobilie unter erleichterten Voraussetzungen mit Erfolg auf einen die Aufklärungspflicht auslösenden konkreten Wissensvorsprung der finanzierenden Bank im Zusammenhang mit einer arglistigen Tauschung des Anlegers durch unrichtige Angaben der Vermittler, Verkäufer oder Fondsinitiatoren berufen können.

\section{Ausblick}

Sollten wir uns im Bankrecht möglicherweise aufgrund der Erweiterung und Vertiefung des Verlagsprogrammes von C.H. Beck in einem grundlegenden Paradigmenwechsel befinden? Könnte es sein, daß die Verwissenschaftlichung dieses großen Gebietes auch und gerade unter Zuhilfenahme des Verlagsprogrammes von C.H. Beck dazu führt, daß Kontroversen und Widersprüche im Rechtssystem stärker profiliert und offengelegt werden, als dies früher möglich war? - Ausgeschlossen ist das nicht, denn eine geäußerte und veröffentlichte Meinung wird von vielen wahrgenommen, bekommt auf diese Weise Gewicht. So gesehen spricht vieles dafür, daß die starke Erweiterung des Programms des C.H. Beck-Verlages auch im Bank- und Kapitalmarktrecht mit dazu geführt hat, daß wir in unserer Gesellschaft rechtliche Konflikte pointierter, schärfer und prägnanter austragen. Das führt auf Dauer zu einer Vertiefung und Verbesserung der Rechtskultur, die uns allen zugute kommt. An dieser Aufgabe positiv und konstruktiv mitgewirkt zu haben, ist mit Sicherheit ein bleibendes Verdienst des C.H. Beck-Verlages.

51 XI ZR 6/04 ZfIR 2006, 623. 
https://doi.org/10.17104/9783406731181-503, am 26.04.2023, 16:22:31

Open Access - (c) EY EY - http://www.beck-elibrary.de/agb 